\title{
CONCRETIZAÇÃO DA MORADIA PELO JUDICIÁRIO: POTENCIALIDADES E RISCOS
}

\author{
CONDUCTING THE HOUSING BY THE JUDICIARY: POTENTIALITIES AND RISKS
}

\section{Lauro Gurgel de Brito}

Doutor em Direito pela Universidade de Brasília (UnB). Mestre em Direito Constitucional pela Universidade Federal do Rio Grande do Norte (UFRN). Graduado em Direito pela Universidade do Estado do Rio Grande do Norte (UERN). Professor Adjunto da Universidade do Estado do Rio Grande do Norte (UERN). Advogado.

\section{Jailson Alves Nogueira}

Mestrando em Ciências Sociais e Humanas e Graduado em Direito pela Universidade do Estado do Rio Grande do Norte (UERN). Membro do Grupo de Pesquisa do Pensamento Complexo (GECOM-UERN).

\section{Resumo}

Este artigo analisa as formas de efetivação do direito à moradia urbana em nível local. A questão central consiste em investigar a possibilidade de concretizá-lo mediante decisão judicial, em casos concretos. São discutidos o conceito, a importância, a metodologia e os paradigmas hermenêuticos da interpretação constitucional, bem como o respectivo círculo de intérpretes. Também são abordadas as semânticas da expressão moradia, promovendo os cortes epistemológicos até a caracterização do direito fundamental social à moradia e a competência política para garanti-lo. E, com base num caso de reintegração de posse, são avaliados as potencialidades e os riscos da decisão judicial no Estado Democrático de Direito. Os resultados demonstram que a tarefa de concretizar o direito à moradia urbana incumbe prioritariamente à Administração Pública, na forma de políticas habitacionais. Todavia, a decisão judicial também poderá fazê-lo, quando tais políticas se mostrarem insuficientes ao cumprimento da Constituição e à proteção de interesses indisponíveis, mormente quando presentes pessoas em situação de vulnerabilidade socioeconômica. Acolhida essa tese, abre-se um pórtico de opções criativas ao magistrado, adiando a reintegração de posse, evitando o despejo e o desamparo de famílias, pelo menos até que Ihes possam ser garantidas, minimamente, condições habitacionais dignas. Embora haja riscos 
nessa escolha metodológica, eles podem ser neutralizados no debate público. Portanto, na solução do caso é possível e necessário atingir o mesmo fim (restauração da posse), sem anular direitos fundamentais dos afetados pela decisão.

Palavras-chave: Estado Democrático de Direito. Judicialização da moradia. Concretização.

\begin{abstract}
This article analyzes the forms of realization of the right to urban housing at the local level. The central question is to investigate the possibility of implementing it by judicial decision, in concrete cases. The concept, importance, methodology and hermeneutic paradigms of constitutional interpretation, as well as the respective circle of interpreters, are discussed. The semantics of housing expression are also addressed, promoting the epistemological cuts to the characterization of the fundamental social right to housing and the political competence to guarantee it. And, based on a case of reintegration of possession, the potentialities and risks of the judicial decision in the Democratic State of Law are evaluated. The results demonstrate that the task of realizing the right to urban housing is a priority for the Public Administration, in the form of housing policies. However, the judicial decision may also do so, when such policies prove to be insufficient to comply with the Constitution and to protect unavailable interests, especially when people present in situations of socioeconomic vulnerability. Once this thesis is accepted, a portico of creative options opens to the magistrate, delaying the reintegration of possession, avoiding the eviction and abandonment of families, at least until they can be guaranteed, minimally, decent housing conditions. Although there are risks in this methodological choice, they can be neutralized in the public debate. Therefore, in the solution of the case it is possible and necessary to achieve the same purpose (restoration of tenure), without annulling the fundamental rights of those affected by the decision.

Key-words: Democratic state. Judicialization of housing. Implementation.
\end{abstract}




\section{CONSIDERAÇÕES INICIAIS}

Diante do crescente processo de urbanização vivenciado hodiernamente, é relevante e oportuno que se discutam as formas de efetivação do direito à moradia nas cidades, em especial para a população economicamente vulnerável, o que implica em analisar, também, a própria essência da interpretação jurídica.

Nesse sentido, impõe-se averiguar se existe ou não um poder de criação (normativa) por parte do intérprete nesse processo. Tanto que se tem falado em hermenêutica clássica, que reputa a interpretação jurídica como um processo lógicodedutivo de cognição, e em nova hermenêutica, que situa a interpretação do Direito como um processo de criação da norma a partir do texto e do contexto, realizado por um amplo rol de legitimados. Nesse novel paradigma, concebe-se, inclusive, a interpretação e a concretização como comportamentos indissociáveis. Afinal, ainda se deve falar em interpretação da Constituição? Ou seria melhor reportar-se à concretização dos preceitos constitucionais?

Mas, tão importante quanto abordar esses aspectos, é discutir sobre quem são os intérpretes ou concretizadores da Constituição, investigando-se se apenas os órgãos do Poder Judiciário têm essa prerrogativa ou se há mais pessoas com legitimidade para interferir na definição dos conteúdos normativos. Quais os poderes e limites de atuação do magistrado? Qual é o papel do cidadão nesse processo?

Um terceiro aspecto igualmente relevante no estágio atual do constitucionalismo diz respeito ao problema do caráter vinculante dos direitos fundamentais e o consequente dever de concretização ou conformação pelos poderes públicos, incluído o Poder Judiciário. Ao ser elevado a ente da federação brasileira, o município tem responsabilidades que se refere à efetivação do direito à moradia urbana e a sua omissão, ainda que parcial, pode ensejar demandas judiciais e, consequentemente, provimentos jurisdicionais. Qual a forma de garantir esse direito: somente através de políticas gerais (leis) ou pode ocorrer na forma de medida judicial? A resposta a essa indagação é o cerne deste trabalho.

Permeando esses temas, também parece relevante 0 debate acerca das potencialidades (poderes) e dos riscos (limites) de atuação do juiz nas demandas de reintegração de posse quando presentes pessoas em situação de vulnerabilidade socioeconômica. Destarte, o que se pretende refletir aqui é, em síntese, a 
interpretação mais adequada em relação ao vocábulo "moradia", presente no texto da Constituição da República Federativa do Brasil (1988), tomando-lhe como base a dimensão (ou status) do direito (social), com ênfase na forma de concretização em âmbito local e se essa tarefa pode ser realizada na via judicial.

Investiga-se acerca dos métodos e paradigmas de interpretação constitucional e de quem detém legitimidade para concretizar (conformar), em nível municipal, os comandos normativos que introduzem o direito à moradia no nosso ordenamento jurídico. E, ainda, a normatividade (vinculatividade) desses comandos.

Nesse diapasão, afora os elementos pré e pós-textuais, este trabalho se estrutura em três partes essenciais, que se interligam. Primeiramente, são analisados conceitos e métodos da nova hermenêutica, procurando contextualizar a temática interpretativa na quadra do constitucionalismo democrático de direito, considerada a sociedade heterogênea, complexa, globalizada e socialmente desigual, como a brasileira.

Posteriormente, abordam-se possibilidades interpretativas para a possível concretização (conformação) do direito (fundamental) à moradia, consideradas as balizas apresentadas na primeira parte. A partir das semânticas do termo moradia, identificam-se os correspondentes teores normativos.

Por fim, faz-se um estudo de caso, avaliando a política de benefícios e incentivos fiscais, instituída pelo Município de Mossoró, como forma de concretização (conformação) desse direito em nível local, bem como a eventual possibilidade de provimento judicial garantir-Ihe efetividade, diante da insuficiência das políticas públicas. A partir da análise de um procedimento de reintegração de posse de imóvel urbano, enfatizam-se as potencialidades e os riscos dessa opção metodológica de julgamento.

Nesse desiderato, propõe-se uma abordagem dialética, revolvendo conceitos tradicionais e aparentemente inquebrantáveis, como a ideia de concessão liminar inaudita altera pars em reintegração de posse, com base simplesmente em cânone processual, por se tratar de ação de "força nova". Questionando esse paradigma, é possível contextualizar o caso e decidi-lo com base nos diversos elementos que 0 circundam, na perspectiva de atender melhor ao sentimento de justiça e à força normativa da Constituição.

No trabalho, faz-se presente, majoritariamente, a pesquisa bibliográfica, com destaque para as obras de Direito Constitucional e Teoria da Constituição, além do 
exame da legislação pertinente, sem olvidar das informações disponibilizadas nos sítios eletrônicos da rede mundial de computadores e dos dados coletadas junto às repartições públicas.

\section{A NOVA HERMENÊUTICA CONSTITUCIONAL, INTÉRPRETES E MÉTODOS DE INTERPRETAÇÃO}

Sobre essa temática, é importante que se faça uma abordagem acerca das questões pertinentes ao conceito, à necessidade, à tarefa (ou legitimidade) e aos paradigmas hermenêuticos de interpretação constitucional. De modo que se aborda a metodologia dita tradicional (Savigny) e aquela plasmada na denominada Nova Hermenêutica, principalmente na metódica estruturante (Müller) e na proposta de interpretação numa sociedade aberta dos intérpretes da constituição (Häberle), bem como na busca por revisitar a tradição e delinear-lhe a evolução para o que se tem concebido como paradigma hermenêutico do Estado Democrático de Direito (Menelick).

A hermenêutica jurídica tradicional tem em Savigny um de seus expoentes, haja vista ter-Ihe traçado diretrizes que até hoje são amplamente estudadas nos cursos de graduação em Direito. São atribuídos a ele os métodos ou elementos clássicos, de forma que a interpretação das normas pode ser gramatical, sistemática, teleológica e histórica.

Explicando esses métodos, Barroso (2004) faz uma síntese para afirmar que a interpretação normativa parte do texto da norma buscando-lhe o sentido literal (interpretação gramatical), mas também as conexões entre diferentes preceitos (interpretação sistemática), bem com a finalidade (interpretação teleológica) e o respectivo processo de criação (interpretação histórica).

Mas por que se buscar uma nova hermenêutica? A resposta pode ser encontrada em Bonavides (2003), no sentido de que a Constituição na sociedade heterogênea e pluralista atual, de classes e grupos antagônicos e de permanente conflito, possui dimensões de ordem jurídica, política e axiológica. Por isso, surgiram métodos mais dinâmicos e próximos da realidade constitucional. Para ele, as lacunas deixadas pela hermenêutica tradicional, própria do positivismo lógico-dedutivo, não contempla a interpretação de Constituição de estrutura aberta, plúrima e de teor indefinido. 
Assim, segundo Bonavides (2003), nesse novo paradigma interpretativo, a norma, o sistema e os métodos clássicos perdem força e passam a ser apenas pontos de vista (topoi) na medida em que o eixo fundamental é o problema. Ganha importância o discurso persuasivo e a busca pelo consenso, além da tese da materialidade constitucional, que se opõe ao formalismo positivista.

Com efeito, de acordo com Müller (2005), os métodos tradicionais (Savigny) são insuficientes em se tratando de interpretar a Constituição. Ele critica a aplicação do positivismo legalista na seara constitucional, fenômeno por ele denominado de positivismo jusconstitucionalista, consistente em pensar a Constituição como um sistema formal de leis, desconexos da história e da realidade social, sem materialidade e onde se enxerga a unidade entre texto normativo e norma.

Uma das explicações é que as Constituições que tem algumas particularidades, principalmente pelo fato de ser o ordenamento fundante de determinada sociedade (sentido histórico-político). Ainda, as constituições são dotadas de prescrições jurídicas hierarquicamente superiores, cujos âmbitos de regulamentação possuem elevado grau de abertura, como se fossem rendas, malhas com pontos largos.

Numa tentativa de superar esses conceitos tradicionais, aponta-se uma espécie de viragem hermenêutica, que se afirma com a introdução da metódica estruturante. A interpretação, segundo esse pensamento, é aquela que, reconhecendo a insuficiência dos métodos tradicionais (gramatical, sistemático, teleológico e histórico), procura a solução mais justa e adequada a partir da análise do caso a ser interpretado, valorando os diversos pontos de vista e especificidades da situação.

Inicialmente, Müller (2005) aduz que a norma é mais do que um enunciado linguístico, razão pela qual a sua aplicação não se esgota na mera interpretação de um texto normativo. Propõe, então, que se realize a "concretização" da norma ao invés da interpretação do texto da norma. Para tanto, ele apresenta a metódica estruturante, partindo do pressuposto dessa não-identidade entre texto e norma e nem entre interpretação e concretização. A estrutura da norma integra o programa normativo (texto) e o âmbito da norma (recorte da realidade social). Mas, é importante ressaltar, a metódica estruturante não despreza os elementos tradicionais de interpretação, que passam a ser parte do processo de concretização.

Assim, quanto ao conceito, pode-se afirmar que 0 ato de interpretar, considerada a nova hermenêutica, consiste na atividade de criar ou atribuir sentido subjacente aos símbolos linguísticos (textos, enunciados), levando em conta os fatos 
do caso, a fim de se obter uma decisão racionalmente fundamentada, que é a norma propriamente dita. Daí se concluir pela diferença entre enunciado normativo (programa) e norma jurídica propriamente dita (produto da interpretação).

Já no tocante à necessidade, resta evidente que todos os enunciados normativos precisam ser interpretados e concretizados. E uma das explicações para isso pode ser encontrada em Menelick de Carvalho Neto (1998), para quem o Direito moderno caracteriza-se por ter o perfil textual, ou seja, pelo fato de que o acesso às normas jurídicas se dá mediante textos discursivamente construídos e reconstruídos. Em consequência disso, o autor afirma que o trabalho de interpretação ganha maior relevância para a implantação da ordem jurídica. Essa também é a compreensão de Müller (2005), para quem o teor literal de uma prescrição normativa pode ser claro ou mesmo unívoco no papel, mas o caso prático ao qual ela deve ser aplicada pode figurá-la destituída de clareza.

llustrando-se essa doutrina, pode-se perceber que o postulado da isonomia, bem como o direito à moradia, ainda que em princípio, pareçam claros e evidentes ao intérprete, comportam vários sentidos, especialmente quando evidenciado o conteúdo principiológico. Ora, afirmar que todos são iguais perante a lei não basta por si só para cumprimento da vontade constitucional de garantir a igualdade material.

Da mesma forma, o vocábulo "moradia" aparentemente tem um significado bastante claro. Todavia, quando se parte para sua significação normativa, ele pode comportar diferentes resultados exegéticos (posse, propriedade, garantia da privacidade, elemento da dignidade humana, entre outros). E quem delimitará qual sentido deva prevalecer no caso concreto? Os intérpretes.

Quanto à tarefa de interpretar a Constituição, Häberle (1997) reporta-se ao fato de que essa não é uma missão exclusivamente estatal, mas pertencente à sociedade em geral, tanto aos órgãos oficiais (Legislativo, Executivo, Judiciário, Ministério Público e outros), quanto aos órgãos não-oficiais, como as associações e as Organizações Não-Governamentais (ONGs), e até o próprio cidadão individualmente. Para ele, é preciso democratizar a interpretação constitucional e seria impensável isso sem o cidadão ativo.

Referido o conceito, demonstrada a imprescindibilidade e identificados os potenciais responsáveis pela interpretação da Constituição, passa-se agora a analisar os métodos apresentados pela hermenêutica com o fito de atingir esse objetivo. Para se desincumbirem de sua importante tarefa, os intérpretes podem se valer dos 
métodos apresentados pela nova hermenêutica (BONAVIDES, 2003). Entre eles, ressaltam-se aqui o método concretista estruturante (Müller) e o método da sociedade aberta dos intérpretes da Constituição (Häberlle).

Pelo método concretista estruturante de Müller, o processo de concretização envolve elementos diversos: o texto ou enunciado (programa normativo) e o âmbito normativo, que são as condições históricas, políticas, sociais e econômicas subjacentes ao caso. Para ele, um novo enfoque da hermenêutica jurídica tem construído a tese da não-identidade de texto e norma, de forma que o teor literal de uma prescrição juspositiva se constituiria apenas na ponta do iceberg.

Assim, partindo do caso a ser solucionado e procurando encontrar a solução mais justa e adequada, o intérprete deve analisar os diferentes pontos de vista, como o reconhecimento da realidade fática, repercussão política, social e econômica da decisão, unidade e força normativa da Constituição, entre outros, aproximando a constituição formal e a constituição material.

Embora não o diga expressamente, o Supremo Tribunal Federal já adotou esse método, quando reconheceu a existência fática de um município e não anulou a lei estadual inconstitucional que o criara, pois isso, segundo aquele Tribunal, geraria mais transtornos sociais do que benefícios, acolhendo o que denominou de "força normativa dos fatos". No caso da ADI 2.240-BA ficou consignado na ementa do acórdão que:

1. O Município foi efetivamente criado e assumiu existência de fato, há mais de seis anos, como ente federativo. 2. Existência de fato do Município, decorrente da decisão política que importou na sua instalação como ente federativo dotado de autonomia. Situação excepcional consolidada, de caráter institucional, político. Hipótese que consubstancia reconhecimento e acolhimento da força normativa dos fatos. 3. Esta Corte não pode limitar-se à prática de mero exercício de subsunção. A situação de exceção, situação consolidada --- embora ainda não jurídica --- não pode ser desconsiderada. 4. A exceção resulta de omissão do Poder Legislativo, visto que o impedimento de criação, incorporação, fusão e desmembramento de Municípios, desde a promulgação da Emenda Constitucional n. 15, em 12 de setembro de 1.996, deve-se à ausência de lei complementar federal. 5 . Omissão do Congresso Nacional que inviabiliza o que a Constituição autoriza: a criação de Município. A não edição da lei complementar dentro de um prazo razoável consubstancia autêntica violação da ordem constitucional. 6. A criação do Município de Luís Eduardo Magalhães importa, tal como se deu, uma situação excepcional não prevista pelo direito positivo. 7. O estado de exceção é uma zona de indiferença entre o caos e o estado da normalidade. Não é a exceção que se subtrai à norma, mas a norma que, suspendendose, dá lugar à exceção --- apenas desse modo ela se constitui como regra, mantendo-se em relação com a exceção. 8. Ao Supremo Tribunal Federal incumbe decidir regulando também essas situações de exceção. Não se afasta do ordenamento, ao fazê-lo, eis que aplica a norma à exceção 
desaplicando-a, isto é, retirando-a da exceção. 9. Cumpre verificar o que menos compromete a força normativa futura da Constituição e sua função de estabilização. No aparente conflito de inconstitucionalidades impor-se-ia o reconhecimento da existência válida do Município, a fim de que se afaste a agressão à federação. 10 . O princípio da segurança jurídica prospera em benefício da preservação do Município. 11. Princípio da continuidade do Estado. 12. Julgamento no qual foi considerada a decisão desta Corte no MI n.725, quando determinado que o Congresso Nacional, no prazo de dezoito meses, ao editar a lei complementar federal referida no $\S 4^{\circ}$ do artigo 18 da Constituição do Brasil, considere, reconhecendo-a, a existência consolidada do Município de Luís Eduardo Magalhães. Declaração de inconstitucionalidade da lei estadual sem pronúncia de sua nulidade 13. Ação direta julgada procedente para declarar a inconstitucionalidade, mas não pronunciar a nulidade pelo prazo de 24 meses, da Lei n. 7.619 , de 30 de março de 2000, do Estado da Bahia.

A argumentação nesse caso foi toda desenvolvida na perspectiva de uma solução justa e socialmente mais adequada para o caso concreto e não simplesmente no intuito de conservar a integridade do sistema normativo in abstrato. A pretensão foi conciliar o sentimento de justiça e garantia de segurança jurídica. Isso se comprova pelo uso de argumentos como "existência de fato", "situação excepcional consolidada", "força normativa dos fatos", "esta Corte não pode limitar-se à prática de mero exercício de subsunção", "incumbe decidir regulando também essas situações de exceção", entre outros. Por outro lado, considerando o déficit habitacional brasileiro, como o poder público deve se comportar a fim de que se concretize o direito constitucional à moradia? O método de Müller oferece uma importante contribuição argumentativa (BRASIL, 2005).

Já pelo método concretista da sociedade aberta dos intérpretes da Constituição, Häberle afirma que o modelo de interpretação de uma "sociedade fechada" concentra a interpretação da Constituição nos juízes e nos procedimentos formalizados. Por isso, ele critica esse modelo e propõe outro, mediante a ampliação desse rol, a fim de incluir todos os órgãos estatais, todas as potências públicas, todos os cidadãos e grupos. A teoria de Häberle se concentra em três pontos principais: a) no alargamento do círculo de intérpretes da Constituição; b) no conceito de interpretação como um processo aberto e público; e c) na concepção de Constituição como realidade construída.

Nessa metodologia, há uma espécie de ponte que liga o intérprete comum ao hermeneuta profissional (jurista). Assim, ao se referir ao citado conceito republicano de interpretação, ele apresenta um catálogo que inclui, além dos órgãos oficiais, os partidos políticos, as organizações sociais e até os cidadãos como intérpretes da 
Constituição. A essa altura, é inevitável acrescer que as pessoas atingidas por questões constitucionais são intérpretes. Ou seja, "também os atingidos que participam da vida jurídica e da vida da constituição desempenham funções efetivas de concretização da constituição" (MÜLLER, 2005, p. 35),

No sistema jurídico brasileiro, esse método fica perceptível quando é aceito o ingresso do amicus curiae nas ações do controle de constitucionalidade no âmbito do Supremo Tribunal Federal, bem como nas audiências públicas que esse tribunal realiza para discussão e amadurecimento dos grandes temas (uso de células-tronco, proibição da importação de pneus usados e ações afirmativas, entre outras).

Ver-se que os métodos concretistas de interpretação não se aplicam apenas no âmbito do Poder Judiciário. Afinal, como se afirmou, em função da democratização do processo de interpretação, os legisladores e os administradores públicos são legítimos intérpretes-concretizadores da Constituição e, principalmente, não precisam aguardar um posicionamento dos tribunais quando às possibilidades exegéticas. Assim, todos os métodos da nova hermenêutica são importantes ao abrirem um leque com opções metodológico-argumentativas ao intérprete, na tarefa de concretização constitucional cotidianamente.

Portanto, unindo a dimensão tópico-concretista do método de Müller à proposta de ampliação do círculo de intérpretes (Häberle), não resta dúvida de que o Poder Legislativo e o Poder Executivo municipal são legítimos intérpretes da Constituição e diretamente responsáveis pela concretização (conformação) desta no que refere ao direito à moradia. Mas, o Poder Judiciário também não o seria quando devidamente provocado?

Pode haver afirmação do Direito pelo juiz? A Constituição brasileira de 1988 decreta um Estado Democrático de Direito. Qual a consequência política disso para o Poder Judiciário, sobretudo para os magistrados em particular? É possível explicar o protagonismo atual vivenciado pelos juízes brasileiros no que se refere à afirmação do Direito? Essas são questões que encontram resposta e eco na história das organizações políticas e na evolução do constitucionalismo. Para respondê-las, podese trabalhar com a concepção de paradigma e aplicá-la aos sucessivos estágios da organização político-constitucional ocidental.

Por paradigma entende-se aqui o modelo, padrão ou mapa amplamente reconhecido e utilizado pela ciência para fins de classificar determinados elementos. Diante de uma situação de crise, determinado paradigma é questionado e pode ser 
sucedido por outro, o que caracteriza uma revolução científica. Partindo dessa concepção, Menelick de Carvalho Neto (1998) consegue identificar dois grandes paradigmas de hermenêutica constitucional: a pré-modernidade e a modernidade. Esta se subdividindo em três outros: Estado de Direito, Estado de Bem-Estar Social e Estado Democrático de Direito. Para construir o seu pensamento, o autor elege o conteúdo do Direito e o protagonismo político dos órgãos na interpretação e aplicação das normas jurídicas.

Dessa forma, ele aponta que, na pré-modernidade (antiguidade e idade média), o Direito era um conteúdo vindo de alguém superior, que emanava de legislações, costumes, tradições e usos locais, sendo marcadamente casuístico e individual, sem viés de abstração e generalidade, para consagrar os privilégios de casta. Notabilizase o Direito, de tal modo, numa indissociabilidade entre religião, direito, moral, tradição e costumes.

Com a modernidade, vem o paradigma do Estado de Direito, surgindo a percepção de sistema normativo de regras gerais e abstratas, válidas universalmente para todos os membros da sociedade determinada (Estado Nacional) e vinculante inclusive em relação ao Estado. Nesse estágio, a centralidade hermenêutica pertence ao Poder Legislativo, tanto que o juiz é tido apenas como se fosse a boca que pronuncia a lei, sem poder de interpretar-Ihe o conteúdo. A expressão "juiz boca da lei" se faz presente na obra de Montesquieu (1996). Com efeito, procurando demarcar a prevalência (autoridade suprema) do legislador na interpretação ou palavra final sobre o conteúdo da lei, o filósofo iluminista alude que o poder de julgar é, de alguma forma, nulo e os juízes da nação são apenas "a boca que pronuncia as palavras da lei" ou "serem inanimados" que não podem moderar a força e o rigor da lei.

Já no paradigma do Estado Social, surgem os direitos coletivos e sociais, numa sociedade carente de acesso à educação, à saúde e à previdência. $\mathrm{O}$ padrão hermenêutico passa a se caracterizar pelas análises teleológicas, sistêmicas e históricas, capazes de emancipar o sentido da norma, a vontade objetiva da lei. Isso tudo em contraposição à atividade mecânica do juiz e à vontade subjetiva do legislador, típicas do estágio anterior.

Por fim, no paradigma do Estado Democrático de Direito, o Direito é participativo, pluralista e aberto e o padrão hermenêutico avoca o Poder Judiciário para a centralidade da interpretação e aplicação (concretização) do Direito. Assim, o juiz precisa de sensibilidade para interpretar os fatos, aplicando o Direito diante do 
caso a ser julgado, satisfazendo tanto à legalidade (segurança jurídica) e quanto ao sentimento de justiça, que deflui da adequabilidade do julgado às particularidades do caso concreto.

Nesse prisma, não deve parecer estranho que o juiz determine, à luz dos fatos que circundam o caso, o cumprimento de medidas que assegurem direitos fundamentais do cidadão. No Estado Democrático de Direito, o juiz pode condenar o Poder Público a inscrever uma família desabrigada numa política pública de acesso à moradia, por exemplo? A questão será analisada no item seguinte.

\section{DIREITO À MORADIA: LEITURA A PARTIR DA CONSTITUIÇÃO DE 1988}

Uma das características do Direito na modernidade consiste na sua emanação de textos ou enunciados linguísticos, todos sujeitos a manipulações no momento da aplicação, a depender do interesse de quem os pretende interpretar e aplicar (CARVALHO NETO, 2006). Assim, a presença do termo moradia no corpo da Constituição de 1988 não se revela suficiente, por si só, para tornar efetivo o acesso das famílias a um lar digno, principalmente na concepção de direito social, a depender de políticas públicas.

A proposta deste item é problematizar "moradia", a partir das seguintes indagações: quais as possíveis acepções desse termo? Qual o sentido mais adequado à vontade constitucional de superar o déficit habitacional brasileiro? Qual a dimensão da moradia no elenco dos direitos humanos e dos direitos fundamentais?

Vistos, ainda que de modo resumido, os métodos de interpretação gravados pela nova hermenêutica, parte-se agora para a interpretação do vocábulo moradia, a fim de se chegar à dimensão possível e adequada do direito fundamental correlato a ele. Mas é preciso antes delimitar o objeto de estudo, fazendo-se a opção semântica a partir da Constituição.

A semântica pode ser entendida como a área do conhecimento que estuda a significação e as mudanças de sentido das palavras no tempo e espaço. Diante disso, faz-se oportuna a compreensão de que alguns sentidos podem ser atribuídos ao termo moradia, presente no Texto Constitucional.

Em face disso, pode-se fazer um corte epistemológico e optar-se por um ou mais desses sentidos. Assim, apontam-se vários significados, como a sua vinculação com o mero direito de propriedade a um imóvel residencial (casa própria). Mas 
entende-se que pode existir o direito à moradia, mesmo que não haja o acesso à casa própria e não se tenha direito real de propriedade sobre o local de residência da família. Nessa linha, inclusive, concebe-se que "o direito à moradia não é necessariamente direito à casa própria. Quer-se que se garanta a todos um teto onde se abrigue com a família de modo permanente" (SILVA, 2008, p. 314).

Também existe a dimensão negativa do direito fundamental à moradia, enquanto instrumento garantidor da defesa da intimidade, da privacidade, protegido pela inviolabilidade de domicílio, gerando para o Estado e para as demais pessoas o dever de abstenção, de não retirar o direito de quem já o detém ou de impedir alguém de consegui-lo licitamente.

Outra possibilidade referencial, aqui, diz respeito ao conteúdo do termo "moradia" sob o prisma dos direitos fundamentais sociais, na dimensão prestacional. Considerada a doutrina desenvolvida por Jellinek sobre os quatro status em que o indivíduo pode encontra-se em face do Estado, aqui se apresenta apenas o status civitatis (ou positivo), como um direito a ser concretizado por ação do Estado (MENDES; COELHO; BRANCO, 2010).

$\mathrm{Na}$ ordem normativa internacional, $\mathrm{o}$ direito à moradia tem integrado tradicionalmente o conjunto dos direitos humanos, constituindo-se agora também numa das metas do desenvolvimento sustentável (ONU, 2015). Com efeito, durante a Cúpula da Organização das Nações Unidas sobre o Desenvolvimento Sustentável, em 2015, ocorrida em Nova York, foi aprovada, pela unanimidade dos 193 Estadosmembros daquela entidade, a Agenda de Desenvolvimento Sustentável das Nações Unidas. Nela, são anunciados 17 objetivos globais e 169 metas, a serem cumpridos até o ano de 2030, todos integrados, indivisíveis e que equilibram as três dimensões do desenvolvimento sustentável: econômica, social e ambiental.

O documento se apresenta como um plano de ação dirigido às pessoas, ao planeta e à prosperidade, buscando fortalecer a paz universal com mais liberdade e reconhecendo que a erradicação da pobreza em todas as suas formas e dimensões, incluindo a pobreza extrema, que é o maior desafio global e um requisito indispensável para o desenvolvimento sustentável. O objetivo 11 é dedicado ao ambiente urbano, visando "tornar as cidades e os assentamentos humanos inclusivos, seguros, resilientes e sustentáveis", a partir da compreensão de que o desenvolvimento desse espaço é fundamental para a qualidade de vida das pessoas. Assim, entre as metas a serem alcançadas até o ano de 2030, surge o compromisso de garantir o acesso à 
habitação segura, adequada e a preço acessível.

No que se refere ao sistema normativo brasileiro, a moradia se insere no quadro

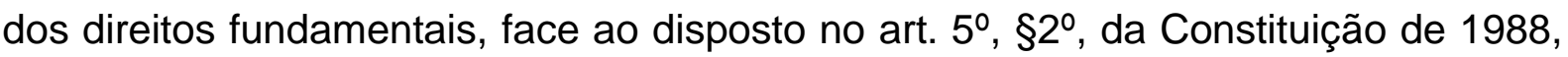
que institui a cláusula de abertura para outros direitos. Com Silva (2008), entende-se que os direitos sociais fundamentais (saúde, educação, moradia, entre outros) são prestações positivas proporcionadas pelo Estado, enunciadas em dispositivos constitucionais, que possibilitam melhores condições de vida aos mais fracos, direitos que tendem a realizar a igualização de situações sociais desiguais. Ressaltando-se que, conforme o Relatório de Desenvolvimento Humano de 2014, o Índice de Desenvolvimento Humano (IDH) do Brasil corresponde a 0,744 , pondo-o na $84^{\mathrm{a}}$ posição, entre 187 países analisados (PNUD, 2013).

Com os direitos sociais fundamentais, a pretensão da Constituição de 1988 é assegurar uma melhor condição de vida às pessoas mais pobres, sobretudo diante de um cenário de forte desigualdade social. O Estado tem o dever de, por exemplo, promover políticas que garantam às famílias carentes o acesso à moradia digna. De fato, já na primeira referência expressa da Constituição de 1988 ao termo moradia, a intenção é integrá-la ao rol de direitos fundamentais sociais, ao lado de outros direitos de igual relevância. Assim, o artigo $6^{\circ}$ prevê que "são direitos sociais a educação, a saúde, a alimentação, o trabalho, a moradia, o lazer, a segurança, a previdência social, a proteção à maternidade e à infância, a assistência aos desamparados, na forma desta Constituição" (grifo nosso).

Sobre essa escolha, Sarlet (2003) defende que tal inserção apenas ratifica o que implicitamente já estava consignado, tendo em conta a circunstância de que a moradia guardaria conexão direta com as necessidades vitais da pessoa humana. Assim, para o autor, já se poderia partir da premissa de que a nossa ordem constitucional original já consagrava um direito fundamental implícito à moradia. Com efeito, não há como dissociar o valor (princípio) dignidade humana (ou existência com dignidade) do direito a uma moradia em ambiente saudável, estruturado e seguro em relação às intempéries naturais e humanas, especialmente as decorrentes da criminalidade.

Ainda segundo Sarlet (2003), pelo caráter existencial e por ser expressão do próprio direito à vida, o direito à moradia ocupa lugar similar ao direito à alimentação, integrando aquilo que na esfera internacional tem sido designado de direito a um adequado padrão de vida, denominado de mínimo existencial. Para Torres (1989), 
não existe um conteúdo específico nesse sentido, abrangendo qualquer direito, desde que seja essencial e inalienável, que assegure as condições para o exercício da liberdade e da felicidade humana. Assim, por exemplo, no concernente aos indigentes e às pessoas sem-teto, a moradia é direito fundamental e integra o mínimo existencial, tornando obrigatória a prestação do Estado.

Portanto, com esse primeiro uso do vocábulo "moradia", há de se projetar a interpretação no sentido de que a Constituição de 1988 vincula que se garanta ao cidadão o direito a uma moradia digna. O que não se traduz na obrigação do Poder Público distribuir moradias aleatoriamente, mas sim no dever de implantar políticas habitacionais que atendam a essas demandas, conforme alerta Saule Júnior (2001).

A propósito, por se tratar de um direito social fundamental, todos os poderes

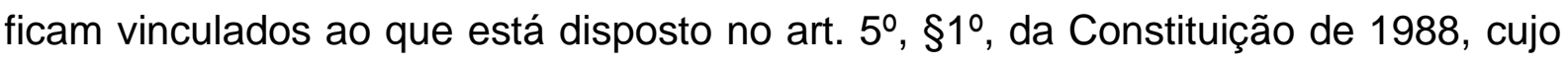
texto assegura que "as normas definidoras dos direitos e garantias fundamentais têm aplicação imediata". Para Dimoulis e Martins (2008), efeito imediato dos direitos fundamentais implica no seguinte: a) vincula todas as autoridades do Estado, inclusive o Poder Legislativo; e b) os titulares dos direitos não precisam aguardar autorização ou concretização estatal, cabendo ao Judiciário apreciar casos de violação. Embora reconheçam que, em se tratando de direitos sociais prestacionais, existe a dificuldade prática de aplicá-lo de imediato.

No artigo $7^{\circ}$ da Constituição de 1988, a moradia aparece como o primeiro elemento integrante do conteúdo normativo do salário mínimo, a ser fixado em lei. Assim, recebe a natureza e a qualificação de direito afeto às necessidades vitais básicas do trabalhador e de sua família.

A propósito dessa temática, é pertinente asseverar que a Lei oㅡ 12.382/2011, a qual dispõe sobre o salário mínimo nacional em 2011, no seu artigo $2^{\circ}$, $\S 1^{\circ}$ estabeleceu os critérios de atualização salarial entre os anos de 2012 e 2015 de acordo com os Índice Nacional de Preços ao Consumidor - INPC. Ainda, no seu artigo $3^{\circ}$, autorizou que os reajustes sejam feitos por decreto do Poder Executivo, o que gerou celeuma e questionamento junto ao Supremo Tribunal Federal (ADI - 4568) ao argumento de que o salário mínimo deveria ser sempre fixado em lei em sentido estrito e não por decreto.

Diante disso, Supremo Tribunal Federal concluiu pela constitucionalidade dessa forma de reajuste, entendendo que esse decreto não inova a ordem jurídica, pois apenas publica os critérios previamente fixados pela lei. Assim, o STF, por 
maioria e nos termos do voto da Relatora, julgou improcedente a ação direta. Mesmo que fixado por Decreto, o valor do salário mínimo deve proporcionar o exercício do direito à moradia.

\section{CONCRETIZAÇÃO DO DIREITO À MORADIA EM ÂMBITO LOCAL}

A previsão constitucional de um direito, expresso em preceito normativo, geralmente de teor principiológico, de estrutura aberta e de conteúdo abstrato e indeterminado, representa apenas o começo de sua institucionalização. Consiste apenas a ponta do iceberg, a demandar uma série de comportamentos, tanto dos interessados quanto dos agentes públicos, que se traduz no processo de interpretação e concretização, até ocorrer a plena satisfação no mundo dos respectivos titulares.

A proposta aqui consiste em inquirir o conceito de concretização e sua aplicação ao direito à moradia, abordando a questão da competência política para realizá-lo e a possibilidade de atuação do Poder Judiciário nessa tarefa. Essas análises serão feitas a partir de um caso real, que envolveu a ocupação de terreno privado, a ação de reintegração de posse e o consequente desfecho, que deixou famílias desabrigadas.

Concretização ou conformação? Recorre-se ao constitucionalista português $\mathrm{J}$. J. Gomes Canotilho para se explicitar o que seja concretizar e conformar em termos de direitos fundamentais. O autor afirma que "muitas normas legais pretendem completar, complementar, densificar, concretizar, o conteúdo fragmentário, vago, aberto, abstrato ou incompleto, dos preceitos constitucionais garantidores dos direitos fundamentais" (CANOTILHO, 2003, p. 1.263-1263).

E explica também que as normas legais conformadoras seriam aquelas que complementam, dão a precisão, concretizam ou definem o conteúdo de proteção de um direito fundamental, abrindo possibilidades de exercício desse direito, tendo em vista que, às vezes, os direitos fundamentais carecem, para o seu exercício, de uma interposição do legislador, nascendo para este a tarefa de legislar.

Afinal, considerando essas premissas, há ou não distinção entre conformar e concretizar? Canotilho aponta distinções, no sentido de que, na conformação, a mediação legislativa é necessária, enquanto que, na concretização, essa mediação seria prescindível, muito embora seja benéfica por alargar e melhorar o exercício do direito. 
Todavia, reconhece, logo em seguida, que "a conformação implica, em alguma medida, um pedaço de concretização", com o que se concorda, uma vez que, independentemente da nomenclatura, o mais importante é realizar no plano fático o que prescreve a Constituição.

A partir dessas lições, a explicação prévia é, portanto, no intuito de esclarecer ao leitor que, para efeito deste trabalho, as expressões "concretização" e "conformação" são sinônimas.

A relevância social da moradia justifica a inserção da competência comum da União, dos Estados, do Distrito Federal e dos Municípios para promover as ações na área da moradia e do saneamento básico das cidades, essa é a previsão do artigo 23, inciso IX da Constituição Federal de 1988.

Ora, como se cuida de uma competência comum, é inegável o dever estatal de planejar, criar, executar e avaliar políticas públicas nesse sentido, o que é extensivo a todos os entes da federação, que devem manter-se articulados, numa espécie de pacto pelo bem-estar, com vistas a concretizarem ou conformarem esse direito.

Portanto, os poderes públicos locais, enquanto intérpretes da Constituição, devem adotar medidas legislativas e administrativas que concretizem essa determinação constitucional pela via de políticas públicas de habitação. Em outras palavras, constata-se um dever e uma necessidade de concretização. O que vem reforçado pelo disposto no art. 182 da Constituição de 1988, que estatui a obrigatoriedade de política urbana a ser executada pelo poder público municipal, inclusive conformando já a finalidade, que seria ordenar as funções da cidade e garantir o bem-estar dos seus habitantes.

No município de Mossoró, cuja sede está localizada na região Oeste do Estado do Rio Grande do Norte, a 280 quilômetros de Natal, capital desse Estado, existe uma política pública conformadora do direito à moradia, pois, no uso de sua competência legislativa, esse ente federativo instituiu, mediante lei, um sistema de benefícios e incentivos fiscais vinculados exclusivamente à construção de unidades habitacionais realizadas no âmbito do Programa Minha Casa Minha Vida1.

Assim, de acordo com a Lei Municipal no 2.496/2009, tendo em vista a garantia de acesso à moradia digna, o Município de Mossoró poderá adotar os seguintes benefícios e incentivos: a) doar terreno ao Fundo de Arrendamento Residencial 
visando a beneficiar famílias com renda de até 10 (dez) salários mínimos; b) isentar essas famílias do pagamento de IPTU até o ano de 2019; c) isentar de ITBI os imóveis residenciais no âmbito do Programa Minha Casa Minha Vida; d) conceder isenção de ISS relativamente aos imóveis residenciais construídos no âmbito desse programa federal, desde que para beneficiar famílias com rende de até 10 (dez) salários mínimos; e) isentar de preços públicos, taxas e/ou tarifas municipais relacionadas com a emissão de alvarás, licenças e outras medidas necessárias à aprovação de projetos arquitetônicos tenham a finalidade de beneficiar as famílias amparadas pelo Programa Minha Casa Minha Vida.

Portanto, com a implantação dessas medidas, o município de Mossoró exerceu um importante papel constitucional, promovendo meios de acesso à moradia digna para as famílias com renda de até 10 (dez) salários mínimos e que estejam amparadas pelo Programa Minha Casa Minha Vida, do governo federal. Trata-se de uma política pública salutar, que se constitui num bom exemplo de parceria e cooperação entre o Município e a União, tendo em vista o equilíbrio do desenvolvimento e do bem-estar da comunidade, na forma pretendida pela Constituição da República Federativa do Brasil.

Essa política se mostra adequada, portanto, à nova hermenêutica constitucional, na medida em que, num contexto de desigualdade social e notório déficit habitacional existente no país, compatibiliza-se com o postulado concretista de afirmação dos direitos fundamentais.

Todavia, ainda se poderia analisar essa política sob o prisma do princípio da proibição da proteção insuficiente, no sentido de se investigar até que ponto ela é materialmente suficiente para, em cumprimento à competência que lhe foi outorgada constitucionalmente, garantir o direito social à moradia. E na hipótese de demandas judiciais cuja procedência pode levar à própria negação desse direito? Quais as potencialidades e os riscos da decisão judicial no caso de uma reintegração de posse, com despejo forçado de sujeitos? Essa temática será abordada a seguir, a partir de um caso real.

\section{O DIREITO À MORADIA PELA VIA JUDICIAL: ESTUDO DE CASO}

Sobre esse enfoque, é importante abordar um caso ocorrido em Mossoró. No ano de 2013, noticiou-se uma reintegração de posse no bairro denominado 
Quixabeirinha ${ }^{2}$, ocasião em que dezenas de famílias foram forçadas, por medida judicial, a desocuparem uma área urbana, irregularmente ocupada. O caso ganhou mais notoriedade pelo fato de que uma das famílias retiradas do local ficou sem moradia, restando-Ihe se abrigar sob um juazeiro ${ }^{3}$, árvore muito conhecida no Nordeste do Brasil porque, mesmo em época de estiagem, nunca perde a folhagem, sendo sua sombra muito utilizada pelos animais para descansam nos horários mais quentes.

Uma das manchetes disponíveis no site "O câmera", em 2015, estampava o seguinte conteúdo: "Em Mossoró, Justiça coloca família no meio de rua e entra de recesso". Trata-se de uma mensagem direta, carregada de ironia e criticidade, desafiando paradigmas tradicionais acerca das decisões judiciais: em determinados casos, para se realizar a justiça, é suficiente proferir a decisão e determinar-lhe o cumprimento? Do corpo da notícia, pode-se extrair o seguinte:

Uma ordem de reintegração de posse na rua Raimunda Luzia da Conceição, no bairro Quixabeirinha movimentou policiais, oficiais de justiça, advogados e a imprensa de Mossoró no final da tarde de quinta feira 08 de agosto de 2013. Representantes da 5 ${ }^{\text {a }}$ Vara Cível da comarca de Mossoró, determinaram a desocupação imediata da residencia de numero 175 , pertencente a dona de casa "Antonia Elizete Dantas de Lira" e pegou toda a família de surpresa. Cerca de 08 pessoas, sendo 05 adultas e 03 crianças, incluindo uma de colo moram na residencia.

Ainda de acordo com as informações, cuidava-se da reintegração de posse de uma área "medindo cerca de 100 estádios de Futebol", há quase 40 anos pertencente a um corretor de imóveis da cidade. E continua o relato noticioso:

(...) o terreno estava loteado para ser vendido, mas uma parte foi invadida há cerca de 14 anos e ele pediu a reintegração na justiça. Ainda segundo o corretor, são cerca de 40 imóveis construídos de forma irregular e a justiça já autorizou a desocupação de forma coletiva. No caso da desocupação de hoje, a família era reincidente, segundo (...) [o corretor]. A Família desabrigada alega que comprou o terreno, construiu um casebre há 14 anos e há 5 , foi incluído no programa de melhorias habitacional da Prefeitura Municipal de Mossoró. A casa foi toda construída em alvenaria, com sala, dois quartos, cozinha e banheiro. (...). O advogado que representa as famílias, lamenta a atitude da justiça, autorizar a retirada da família e não existir um plantão onde reclamar. A justiça entrou em recesso. A família de dona Elizete Dantas, assistiu a retirada e a colocação seus poucos moveis no meio da rua e diz

\footnotetext{
2 Diminutivo da palavra Quixabeira, árvore do bioma caatinga, típico do Nordeste brasileiro.

3 Árvore alta e copada da família das ramnáceas (Zizyphus joazeiro), característica da caatinga nordestina, de folhas trinérveas, flores pequeninas, fruto drupáceo, amarelo, com polpa edule, e cuja casca é rica em saponina e serve como sabão e dentifrício. Fornece ao gado sombra e alimento, não perdendo a folhagem durante a seca (FERREIRA, 2004).
} 
não ter pra onde ir e nem onde colocar os moveis. Todo trabalho dos representantes da Justiça "Oficiais" foi acompanhado de forma passiva pela policia militar de Mossoró. Emocionada e revoltada a família assistiu tudo.

A notícia diz respeito a uma ação de reintegração de posse com pedido de liminar, que tramitou na $5^{\mathbf{a}}$ Vara Cível da Comarca de Mossoró e se encontra arquivada (Processo no 106.08.004577-9). No caso, o autor alegou que era o proprietário e legítimo possuidor do imóvel ocupado, destinado a um loteamento, aduzindo que, na época do esbulho, tentou convencer os "invasores" de que o terreno não estava abandonado, pedindo para que deixassem o referido imóvel, mas não teria obtido êxito. Chama atenção o fato de que na petição inicial, a parte demandada foi identificada como "invasores (sem teto)".

Assim, argumentou não lhe ter restado alternativa, a não ser a ação de reintegração de posse, inclusive com pedido de liminar, por se tratar de ação de força nova, dispensando-se a oitiva da parte ré e a realização de audiência de justificação da posse.

Em decisão interlocutória, a juíza do caso entendeu que o autor comprovara a posse $^{4}$ e a situação de esbulho ${ }^{5}$, razão pela qual deferiu o pedido de pretensão liminar, antes da citação da parte contrária e sem audiência de justificação de posse, determinando a expedição do mandado reintegrativo e autorizando o uso de força policial, se fosse necessária. A certidão emitida pelos Oficiais de Justiças, presente nos autos, descreve que o ato de reintegração ocorreu na presença de força policial, com uso de máquinas e pessoas providenciadas pelo autor da ação, e que todo o processo durou aproximadamente uma hora e trinta minutos.

Somente depois da desocupação houve a citação dos demandados. $\mathrm{Na}$ contestação, autodenominaram-se de "Grupo de trinta FAMÍLIAS", alegaram ser pessoas socialmente excluídas, justificando a ocupação pela necessidade decorrente da aflição com seca e a fome. Defenderam que pretendiam fixar residência no local e que não se poderia fazer aplicação rigorosa da lei naquela situação.

Assim, pleitearam a reversão da medida através da concessão de efeito suspensivo com o retorno das famílias ao imóvel objeto da ação, bem como a

\footnotetext{
4 "Com efeito, em que pese me encontrar em juízo de cognição sumária, da leitura da documentação referenciada, observo que o demandante comprovou exercer a posse (indireta) sobre o imóvel..." (Processo no 106.08.004577-9, fls. 30).

5 "Noutra quadra, a matéria jornalística de fl. 14 (...), o Boletim de Ocorrência Policial e as ilustrações fotográficas (...), confirmam o alegado esbulho" (Processo $n^{\circ}$ 106.08.004577-9, fls. 30).
} 
realização de audiência com a presença das partes e de representante do Estado, no escopo de buscar uma solução conciliatória e adequada às peculiaridades do caso. Não houve a reversão da medida liminar.

Em seguida, o pedido foi julgado procedente em sentença de mérito, após parecer favorável do Ministério Público. Satisfeita a pretensão autoral, o processo foi arquivado em 2010. Mas, no ano de 2013, o autor requereu-lhe o desarquivamento e solicitou o cumprimento de sentença, haja vista a persistência de alguns dos "invasores". Foi determinada e cumprida nova reintegração de posse.

Esse modelo procedimental de reintegração vem bem descrito e fortemente criticado em Rolnik e Aneas (2015). Verifica-se a documentação da área em disputa, constata-se quem é "o verdadeiro dono" e determina-se a reintegração de posse, solicitando apoio das forças policiais para executar a ação. Onde estaria o problema? Ou seja, "isso não é suficiente para lidar com a complexidade dos direitos presentes nessas situações", pois é notório que "constituição garante não apenas o direito de propriedade, mas também sua função social, além dos direitos civis, políticos e econômico-sociais de todos os brasileiros, o que inclui os moradores de ocupações" (ROLNIK; ANEAS, 2015, s.p.).

No caso, adotou-se, portanto, a opção da hermenêutica jurídica que enxerga a ordem jurídica como um sistema formal e positivista, constituído por regras, cuja interpretação e aplicação se resolvem silogisticamente pelo modelo da subsunção, de acordo com a seguinte estrutura: se $A$, deve ser $B^{6}$. Consoante o paradigma hermenêutico do Estado de Direito, a decisão do caso está(ria) tecnicamente correta, uma vez que calcada na ordem jurídica vigente e assim fundamentada, como exige a Constituição de 1988, em seu artigo 93, inciso IX, o qual prevê que "todos os julgamentos dos órgãos do Poder Judiciário serão públicos, e fundamentadas todas as decisões, sob pena de nulidade...".

A crítica a que se sujeita diz respeito ao fato de ter priorizado as alegações da parte autora e a subsunção dos dispositivos legais do Código de Processo Civil em detrimento dos argumentos dos outros afetados e da proteção integral a direitos fundamentais de pessoas envolvidas na demanda judicial.

Julgou-se um pleito de liminar pelo que foi alegado e documentado pelo

\footnotetext{
${ }^{6}$ Para uma crítica acerca do anacronismo desse modelo, ver CARVALHO NETTO, Menelick de. Racionalização do ordenamento jurídico e democracia. Revista Brasileira de Estudos Políticos, v. 88, p. 81-108, 2003.
} 
demandante, sem oitiva da parte contrária e de outros interessados. Perdeu-se a oportunidade de abrir um debate qualitativo sobre a situação e ampliar-lhe o rol de possíveis soluções. Poder-se-ia chegar ao mesmo resultado pretendido pelo requerente (a reintegração da posse), mas preservando direitos fundamentais das famílias ocupantes do terreno. Diante da tensão subjacente ao âmbito normativo, a solução do caso poderia tomar outro rumo, ganhar outra dimensão, como se observa a seguir.

\section{ANÁLISE DAS POTENCIALIDADES E DOS RISCOS DA DECISÃO JUDICIAL}

De fato, se assumido um pensar dialético, a solução desse caso ganharia outros contornos. Rosalvo Schütz (2015) explica que a dialética pressupõe a tensão entre diferentes, o combate à tese da solução definitiva, da verdade absoluta, ou seja, "onde há vida há inacabamento". Ela representa uma tentativa de aproximação da dinâmica da vida, pois tudo está interligado de forma orgânica e perpassado de contradições.

Assim, alude o autor a necessidade de situar-se num contexto e quanto mais ampla for essa contextualização, mas se aproxima da vida. Citando Hegel, ele lembra que a dialética é o motor da história e que, para Marx, a luta de classes seria o motor dialético da dessa mesma história. Em suma, afirma Schütz:

Pensa dialeticamente quem não aceita verdades prontas e não se satisfaz com afirmações isoladas de seus contextos; quem entende que o mundo, assim como o pensamento, está em constante transformação; quem não desvia o olhar da luta entre oprimidos e opressores; quem, por saber que o mundo está em transformação, sabe que ele pode ser diferente. Por isso, quem pensa dialeticamente pensa crítica e esperançosamente! (SCHÜTZ, 2015, s.p.)

Ora, nos casos onde existem conflitos e pretensões de interesses tão relevantes como os acima relatados, que potencialidades (poderes) se apresentam ao juiz para resolver o embate? Ele pode se pautar no paradigma do Estado de Direito, no formalismo legal, fazendo cumprir regras gerais e abstratas que preveem o direito à propriedade e à posse e, em caso de esbulho, à reintegração do imóvel. Nessa hipótese, a decisão seria vazia de conteúdo social. Comemorada pelo autor, que, no conforto de suas condições materiais, conta com uma estrutura econômica favorável, mas sacrificante para os afetados. Em certo sentido, cuida-se até de conduta 
autoritária, por não ouvir sequer a parte contrária.

Mas pode o julgador se basear nos cânones da nova hermenêutica constitucional, particularmente no método estruturante (Müller), na visão de sociedade aberta dos intérpretes da Constituição (Häberle) e no paradigma do Estado Democrático de Direito (Menelick), numa compreensão de centralidade hermenêutica do judiciário e de materialidade do Direito.

Partindo para essa segunda opção, o magistrado se perguntaria: o Poder Judiciário deve servir apenas ao latifúndio ou também reconhecer o direito das minorias? O ato de transferir a oitiva dos "invasores" para depois da concessão de liminar não seria um contraditório elitista? Dessa forma, poderia ele, inicialmente, trabalhar com a distinção entre o texto da norma e a norma propriamente dita. Em seguida, analisaria os programas normativos (direito de propriedade e posse) e os âmbitos normativos (recorte dos fatos), traduzidos nas circunstâncias do caso, como a natureza da área ocupada, o tempo de ocupação, a função dada à propriedade urbana $^{7}$, a presença ou a ausência do Poder Público no transcurso da ocupação, a proteção de pessoas civilmente incapazes, as consequências da decisão, a reversibilidade ou não de determinados provimentos, a vulnerabilidade econômica das pessoas envolvidas, entre outros elementos.

No momento seguinte, deveria o julgador admitir a participação dos afetados no processo de construção da decisão, ouvindo não apenas as partes, mas também entidades ligadas aos movimentos sociais e os órgãos públicos pertinentes. Assim, qualifica o julgamento a partir da democratização do procedimento, ampliando o rol de intérpretes do caso, garantindo a aplicação mais correta do princípio constitucional garantidor da propriedade, bem como a justiça verdadeiramente exigida para as circunstâncias.

Ressaltando o fato de que, em relação à titularidade da interpretação, é falsa a oposição entre o Estado e a sociedade como se apenas os órgãos oficiais detivessem a legitimidade para interpretar os preceitos normativos, pois tanto na gênese quanto na aplicação o Direito pertence a uma comunidade aberta de intérpretes da Constituição (CARVALHO NETTO; SCOTTI, 2012).

Diante das circunstâncias a envolverem a querela, o magistrado pode, ainda, antes de decidir acerca da concessão de liminar de reintegração, determinar ao

\footnotetext{
7 Consoante o art. 182, $\S 2^{\circ}$, da Constituição de 1988, a propriedade urbana cumpre sua função social quando atende às exigências fundamentais de ordenação da cidade expressas no plano diretor.
} 
Município que abrigue temporariamente essa família em um local digno, inclusive à custa da Fazenda Pública, e a inscreva imediatamente numa política de acesso à moradia. Com essas medidas, o juiz concretiza direitos fundamentais (dignidade, moradia, privacidade), realizando a justiça de acordo com a realidade fática, não se limitando a fundamentar a decisão em enunciados normativos genéricos e abstratos (direito à propriedade), de conteúdo indeterminado, pendentes de densificação normativa.

Por outro lado, a que riscos (limites) o juiz se sujeita ao decidir dessa forma? Ele pode ser acusado de estar a afrontar o princípio da separação dos poderes, invadindo esferas de atuação de outrem, usurpando a competência para fixar política pública ou interferindo na definição das prioridades para concessão de moradia, violando o princípio da igualdade. Mas, esses são riscos calculados, plenamente aceitáveis no paradigma hermenêutico do Estado Democrático de Direito, marcado pela necessidade de leitura principiológica da ordem jurídica, principalmente da Constituição. Nesse paradigma, a centralidade se desloca para o Poder Judiciário, garantindo-Ihe a força contramajoritária, extraída da teoria de freios e contrapesos.

Num cenário em que a decisão judicial precisa concretizar princípios (de conteúdo aberto e indeterminado), os riscos são inevitáveis, desafiando todos a enfrentá-los e controlá-los (CARVALHO NETTO; SCOTTI, 2015). São, igualmente, riscos justificáveis, haja vista o bem maior protegido, consistente na segurança da posse para a família, ainda que provisória, permitindo-lhe exercer o direito à privacidade, à intimidade e ao sossego do lar.

É nesse contexto hermenêutico que reside a maior importância da adequada interpretação e aplicação/concretização das disposições normativas, afinal, como afirmava, Montesquieu (1996) todo homem que detém o poder tende a dele abusar, até que encontre um limite. E esse limite é o próprio poder, manifestado por órgão independente. Assim, o Poder Judiciário pode garantir o direito à moradia a partir de uma querela sobre posse imobiliária urbana. Tratar-se-ia de uma típica, válida e legítima concretização do direito à moradia pela via judicial.

\section{CONSIDERAÇÕES FINAIS}

Assim, pode-se perceber que já se reconhece a insuficiência dos métodos tradicionais de interpretação, por isso se desenvolveram métodos mais dinâmicos e, 
ao mesmo tempo, mais próximos da realidade constitucional de uma sociedade plural.

Também, passou-se a entender que 0 ato de interpretar consiste na atividade de criar ou atribuir sentido subjacente aos símbolos linguísticos (textos, enunciados), a fim de se obter uma decisão racionalmente fundamentada (norma propriamente dita).

Nesse sentido, a partir do método concretista estruturante (Müller) e do método concretista da sociedade aberta dos intérpretes da Constituição (Häberlle), observase que a moradia significa, entre outras coisas, ser um direito social prestacional a exigir de todos os entes da federação a implantação de políticas públicas que assegurem esse direito, especialmente aos mais vulneráveis financeiramente.

No município de Mossoró, Estado do Rio Grande do Norte, há uma política de benefícios e incentivos fiscais que viabilizam a concretização do direito à moradia, consistente na doação de terreno e na isenção de alguns tributos municipais, tudo com vistas a beneficiar as famílias amparadas pelo Programa Minha Casa Minha Vida. Assim, ao instituir essa política local de acesso à moradia digna para as famílias com renda mais baixa, o município de Mossoró concretiza preceitos constitucionais.

Todavia, essa política habitacional não tem se mostrado plenamente satisfatória, já que a persistente carência de moradias, conforme restou demonstrado no caso analisado acima. Essa realidade evidencia uma proteção insuficiente ao direito de morar. Diante disso, a via judicial se apresenta como alternativa, abrindo-se um campo de potencialidades, como o abrigo temporário das famílias em um local digno, à custa da Fazenda Pública, e a inscrição delas em política habitacional.

Nas ações de reintegração de posse com pedido de liminar, o magistrado deve avaliar a conveniência do despejo imediato dos ocupantes, pelo menos até que lhes fossem garantidas, minimamente, condições habitacionais dignas. Com isso, evitaria o consequente desamparo das famílias. Embora se reconheça que uma decisão dessa natureza seja carregada de riscos, eles podem ser minimizados a partir de uma compreensão dialética sobre o caso, num cenário de debate público e democrático. 


\section{REFERÊNCIAS}

BARROSO, Luís Roberto. Interpretação e aplicação da constituição. 6 ed. São Paulo: Saraiva, 2004.

BRASIL. Lei no 11.977/2009, de 7 de julho de 2009. Diário Oficial [da União], Brasília, 8 de julho de 2009.

BRASIL. Ministério das Cidades. Secretaria Nacional de Programas Urbanos. Plano diretor participativo. Brasília: Ministério das Cidades, 2005.

BONAVIDES, Paulo. Curso de direito constitucional. 13 ed. São Paulo: Malheiros, 2003.

CANOTILHO, J. J. Gomes. Direito constitucional e teoria da Constituição. 7 ed. Coimbra: Almedina, 2003.

CARVALHO NETTO, Menelick de. A hermenêutica constitucional sob o paradigma do Estado Democrático de Direito. In: Notícias do direito brasileiro. № 06. Brasília: UnB, 1998.

CARVALHO NETTO, Menelick de. Racionalização do ordenamento jurídico e democracia. Revista Brasileira de Estudos Políticos, v. 88, p. 81-108, 2003.

CARVALHO NETO, Menelick de; OLIVEIRA, Marcelo Andrade Cattoni de. Legitimidade e efetividade como tensão constitutiva (conflito concreto) da normatividade constitucional. In: LIMA, Martonio Mont'Alverne Barreto; ALBUQUERQUE, Paulo de Menezes (orgs.). Democracia, Direito e Política: Estudos Internacionais em Homenagem a Friedrich Müller. Florianópolis: Conceito, 2006

CARVALHO NETTO, Menelick de; SCOTTI, Guilherme. Os direitos fundamentais e a (in)certreza do direito: a produtividade das tensões principiológicas e a superação do sistema de regras. Belo Horizonte, Fórum, 2012.

DIMOULIS, Dimitri; MARTINS, Leonardo. Teoria Geral dos Direitos Fundamentais. São Paulo: RT, 2008.

EM MOSSORÓ, Justiça coloca família no meio de rua e entra de recesso. 0 câmera, 2015, Mossoró/RN. Disponível em: http://ocamera.com.br/site/post/4411. Acesso: 13 set. 2015

FERREIRA, Aurélio Buarque de Holanda. Dicionário Aurélio. Eletrônico. 7 ed. Curitiba: Positivo, 2004.

HÄBERLE, Peter. Hermenêutica constitucional. A sociedade aberta dos intérpretes da constituição: contribuição para a interpretação pluralista e "procedimental" da constituição. Tradução: Gilmar Ferreira Mendes. Porto Alegre: Sérgio Antonio Fabris, 1997. 
MENDES, Gilmar Ferreira; COELHO, Inocêncio Mártires \& BRANCO, Paulo Gustavo Gonet. Curso de direito constitucional. 5 ed. São Paulo: Saraiva: 2010.

MONTESQUIEU, Charles de Secondat, Baron de. O Espírito das leis. Tradução: Cristina Murachco. São Paulo: Martins Fontes, 1996.

MOSSORÓ. Lei no 2.496, de 03 de junho de 2009. Institui benefícios e incentivos fiscais vinculados a construções de unidades habitacionais realizadas através do Programa Minha Casa Minha Vida e dá outras providências. Jornal Oficial de Mossoró, Ano II, no 34 - A. Mossoró, 6 de junho de 2009.

SARLET, Ingo Wolfgang. A eficácia dos direitos fundamentais. 4 ed., Porto Alegre: Livraria do Advogado, 2003.

SAULE JÚNIOR, Nelson. Formas de proteção do direito à moradia e de combate aos despejos forçados no Brasil. In: FERNANDES, Edésio (Organizador). Direito urbanístico e política urbana no Brasil. Belo Horizonte: Del Rey, 2001.

SILVA, José Afonso da. Curso de direito constitucional positivo. 30 ed. São Paulo: Malheiros, 2008.

SCHÜTZ, Rosalvo. O que significa pensar dialeticamente? Jornal Mundo Jovem [encarte]. V. 7, no 32, abril de 2015.

TORRES, Ricardo Lobo. O mínimo existencial e os direitos fundamentais. Revista de Direito Administrativo. Rio de Janeiro, no 177, p. 29-49, jul./set. 1989.

Disponível em: http://bibliotecadigital.fgv.br/ojs/index.php/rda/article/view/46113. Acesso em: 28 de mar. de 2019. 